\title{
The medical liability litigation industry and how to defeat it - A challenge for management science
}

Received: 19 February, 2021

Accepted: 24 February, 2021

Published: 25 February, 2021

*Corresponding authors: Howard N Smith, MD, MHA, University of Maryland, USA, Tel: 301-530-5113; E-mail:drhnsmith@aol.com

https://www.peertechzpublications.com

Check for updates

\author{
Howard N Smith* \\ University of Maryland, USA
}

\begin{abstract}
Suspicion of fault is toxic to a trusting relationship between physicians and patients. It is even more toxic to the interest of justice. A medical liability litigation industry rises from this suspicion of fault and prospers at the expense of physicians, patients and justice. Lawyers are part of the medical liability litigation industry; so, too, are expert witnesses, who are also physicians. Byrom vs. Johns Hopkins Bayview Medical Center is illustrative of the impact of suspicion of fault. Inductive reasoning is the conventional way lawsuits are argued. It is the critical success factor used by lawyers and expert witnesses on both sides to showcase their most favorable evidence. However, deductive reasoning is also an acceptable form of legal reasoning. It is completely consistent with the ethical requirement of doctors acting in the capacity of medical experts to remain objective. It analyzes all evidence, favorable or not. Although organized medicine has authority over doctors who are expert witnesses, until now, it does nothing to hold expert witnesses accountable to ethical obligations. The consequences are verdicts like that of Byrom vs Johns Hopkins. Healthcare management science offers a solution to this dilemma. A methodology of deductive reasoning, which is used as a best practice for medical experts, is a means to hold experts accountable to the highest principles of jurisprudence and professional ethics and separates experts from the interests of the medical liability litigation industry.
\end{abstract}

\section{Suspicion of fault and the medical liablity litigation industry}

Medical interventions are not without adverse outcomes. Some may be random; however, some are medical errors. Whether motivated by actual negligence or the suspicion of it, there are 46,000 malpractice suits filed every year [1]. Twice as many claims are opened but not filed. As a result, a medical liability litigation industry evolves in the United States. There are 600 plaintiff firms [2], 700 defense firms [3], 60 medical professional liability companiesm [4], 50 expert witness referral services [5], thousands of medical expert witnesses, 80 special interest groups [6], the American Rule [7], and over 100 tort reforms [8], state and federal. Commerce from the suspicion of fault is at the expense of the patient/doctor relationship. It increases the costs of defensive medicine and liability insurance [9]. It, also, is costly to the interest of justice.

Fundamental to justice is the burden of proof [10]. The burden of proof does not prove cause and effect; rather, it is the means to provide sufficient confidence as to warrant a probability relating cause and effect. In a malpractice case, it is a preponderance of evidence, which corresponds to more likely than not and has a threshold for probability of $50 \%$ plus an ill-defined quantum. For some lawyers, the burden of proof is only $50.01 \%$ probability. However, it could be $95 \%$ probability depending on how the threshold for quantum is set. When quantum is a low bar, exploiting the suspicion of fault is more likely.

\section{Byrom Vs Bayview medical center - A case presentation}

Byrom vs. Johns Hopkins Bayview Medical Center [11], a malpractice case decided on July 1, 2019, illustrates this phenomenon. In October 2014, 16-year-old Erica Byrom starts prenatal care when 23 weeks pregnant. Two weeks later, when 25 weeks, she is admitted to Bayview Hospital for severe pre-eclampsia. Aside from her life being endangered, there are concerns about a poor fetal prognosis. Labor is induced. There is a vaginal delivery of a 670-gram female infant. In the following days, the mother recovers from pre-eclampsia and the very low birth-weight premature infant survives. Later, it is diagnosed with brain damage, microcephaly and cerebral palsy.

\section{Inductive reasoning}

The suspicion of fault inevitably leads to a legal action. To proceed, attorneys need medical experts to review the claim and prepare a report or affidavit of merit, which serves as the 
bases of pleadings. Inductive reasoning is how experts proof their hypothesis of a case. It is equivalent to pulling a coin out of a bag and generalizing that all coins in the bag are the same. In a malpractice lawsuit, the bag is the general principle that, except for the background risk, the standard of care always results in a favorable outcome.

(Figure 1) The coin the plaintiff pulls is an observation that the fetus is normal before admission to Bayview Hospital. Plaintiff attorneys [12] retain several expert witnesses. From medical records, they conclude that, before admission to Bayview Hospital, all evidence points to a normal fetus. Defendant doctors misinterpret sonograms obtained at Bayview Hospital as consistent with a poor prognosis for the fetus, disregarding that, 2 weeks earlier, a sonogram is normal. These experts do not dispute the findings of sonograms at Bayview, but explain them as common in pre-eclampsia. The pre-eclampsia is only a problem for few days, not nearly long enough to cause the brain damage occurring before admission as alleged by the defense. Those sonographic findings are, in fact, fetal indications for cesarean section. Doctors misinform Erica Byrom when she agrees to discontinue electronic fetal monitoring. The tipping point is fetal distress during induction, which is undiagnosed. Because the standard of care for preeclampsia at 25 weeks is induction of labor and cesarean section for maternal and fetal indications, more likely than not, these doctors depart from the standard of care and, if not for them, this child would be normal today.

(Figure 2) The coin the defense pulls is an observation that the fetus is not normal before admission. Defense attorneys [13] retain several expert witnesses. From medical records, they conclude that, before admission to Bayview Hospital, all evidence points to an abnormal fetus. No prenatal care for 23 weeks, low amniotic fluid indices, placental insufficiency, fetal growth restriction, absent end-diastolic umbilical artery blood flow and chlamydia, are all caused by circumstances occurring before October 19, 2014, when admitted to Bayview Hospital. Assertions that the fetus is normal until 25 weeks, never address these circumstances. Erica Byrom understands there is between $65 \%$ and $100 \%$ probability that brain damage already exists and decisions are completely informed. Therefore, more likely than not, there is no departure from the standard of care. If not for these circumstances, this child would be normal today.

Neither argument stands out in stark contrast. Because a threshold for the burden of proof is no greater than more likely than not and because inductive reasoning does not test confidence in either hypothesis, the chance of accepting the wrong hypothesis is high. On July 1,2019 , the jury returns a verdict in favor of the plaintiff [14] - \$229-million, the largest ever recorded in the United States.

\section{Lessons learned from Byrom Vs Bayview medical cen- ter}

Two question remain. First, what does inductive reasoning miss? Logic requires that, if sonographic findings relate to brain damage before admission to Bayview Hospital, there must be some cause before admission. That cause, however, is missing.

Looking closer, eleven words appear in medical records and even in the pleadings [15] "Ms. Byron had recently arrived in the United States from Liberia." These words are the missing link, and, except for oblique references to circumstances occurring before admission to the hospital, jurors remain in the dark about these 11 words when they render their verdict. Without reconciling these 11 words, Byrom vs Bayview Hospital may be a miscarriage of justice and the $\mathbf{2 2 9}$-million verdict is the economic consequence of the suspicion of fault.

Second, if inductive reasoning does not silence these words, what does? Undoubtedly, Erica Byron knows about these words. She is the source. Two perinatologists and a neonatologist at Bayview Hospital know about these words. They hear them from Erica Byrom. Medical experts know about these words. They see them in the medical record. Both plaintiff and defense lawyers know about these words. They hire the experts.

Step 1: Observations -- normal fetus before admission to Bayview Hospital

Step 2: General Principle -.other than the background risk, the standard of care always prevents adverse outcomes.

(A) Standard of care $=$ fetal and/or maternal indications for cesarean section.

(B) Treatment in question = only maternal indications for cesarean section

Step 3: Proof of Hypothesis- Because the fetus is normal before admission, more likely than not, excluding fetal indications for cesarean section caused the adverse outcome. The treatment in question departs from the standard of care. Risk of treatment $>$ the background risk Step 4: Final Report: Certifies that the burden of proof is satisfied but confidence is not tested.

Figure 1: Inductive reasoning - Plaintiff Argument.

Step 1: Observations - abnormal fetus before admission to Bayview Hospital

Step 2: General Principle - other than the background risk, the standard of care always prevents adverse outcomes.

(A) Standard of care $=$ fetal and/or maternal indications for cesarean section.

(B) Treatment in question = only maternal indications for cesarean section.

Step 3: Proof of Hypothesis- Because the fetus is abnormal before admission, more likely than not, excluding fetal indications for cesarean section did not cause the adverse outcome. The treatment in question comports with the standard of care. Risk of treatment $=$ background risk. Step 4: Final Report: Certifies that the burden of proof is satisfied but confidence is not tested.

Citation: Smith HN (2021) The medical liability litigation industry and how to defeat it - A challenge for management science. J Surg Surgical Res 7(1): 026-031. 
Oddly, Erica Byrom is never called to testify. The defendants are never questioned about these words during trial. Except for a report by Dr. Corrine Leach, no expert ever refers to these words. Oddly still, plaintiff attorneys include these words in pleadings. The words contradict the merits of the claim and the judge hears the pleadings. The judge has the discretion to enforce Rule 11 of Federal Rules for Civil Procedures [16], which deals with claims that have no merit, but does nothing. It is as if these words do not exist.

After trial, in a press conference, a spokesperson for Johns Hopkins reveals that discussion of some details is limited by federal law [17]. Because Erica Byrom's immigration status is, arguably, prejudicial, Rule 403 of Federal Rules of Evidence is the likely candidate [18]. Evoking rule 403 in a pretrial proceeding would suppress discussion of details that are unfair and prejudicial. A legal maneuver silences these words.

This bates a third question. Can anything defeat this maneuver? The answer is yes. However, the problem with a motion sustained by a judge is the judge has final authority. A mistrial is denied; a new trial is denied and all parties are bound to the judge's ruling.

\section{Deductive reasoning}

While this maneuver can be defeated, a better strategy is to preempt it. Deductive reasoning preempts this maneuver. Deductive reasoning is a carefully designed method of management science. It is analogous to submitting all the contents of the bag to a methodical quantitative analysis, dismissing nothing. By following the rules, two different conclusions are still possible, but the rules are transparent and any distortion is exposed. It also provides the means to warrant a probability relating cause and effect, but, by maximizing the threshold for quantum in preponderance of evidence, there is greater confidence and a wrong conclusion is less likely (Figure 3).

In step one, the treatment in question and the standard of care are divided into 10 phases corresponding to duties that arise between a patient's first and last encounters with Bayview Hospital. Each phase of the treatment in question is compared to its counterpart in the standard of care, which is the benchmark.

The Presentation Phase is the duty to disclose all risk factors relevant to the initial encounter at Bayview Hospital. The 11 words are the key to risk factors. These risk factors are: (1) Erica Byrom arrives from Liberia in August 2014, when already 17 weeks pregnant. (2) In Liberia [19], substandard prenatal care and teen pregnancies are public health crises. (3) Endemic in Liberia are certain sexually transmitted diseases associated

Step 1- General Principle : other than the background risk, the standard of care always prevents adverse outcomes.

(A) Treatment in Question $\left(\mathbf{T}_{\mathbf{x}}\right)$ - only maternal indications for cesarean section.

1. Presentation Phase -the duty to identify all risk factors relevant to the initial encounter.

2. Investigation Phase -the duty to perform a complete medical work-up.

3. Interpretation Phase -the duty to understand the relevance of all the data in the work-up.

4. Diagnostic Phase -the duty to arrive at an appropriate diagnosis and prognosis

5. Discrimination Phase -the duty to consider applicable alternative management

6. Informed Consent Phase -the duty to disclose risks and complications of the alternatives.

7. Selection Phase -the duty to select the safest effective management from among the choices.

8. Technical Phase -the duty to exercise due caution in each detail of management.

9. Resolution Phase -the duty to respond to progress and complications during recovery.

10. Discharge Phase -duty to follow -up and make certain all documentation is complete

(B) Standard of Care $\left(\mathbf{T}_{\mathbf{s c}}\right)$ - fetal and/or maternal indications for cesarean section-

Same 10 phases - each represent the benchmark

Step 2 -Observation: the adverse outcome:

(A) Adverse Outcome caused by Standard of Care

1. Background Risk $(\mu)=15.2 \%$

2.Relative Risk for the Standard of Care $\left(\mathrm{RR}_{\mathrm{sc}}\right)=\mu / \mu=1.0$

(B) Adverse Outcome caused by Treatment in Question - Compare all 10 phase in treatment in question to corresponding phases in standard of care to compute:

1. Risk of Harm $(\mathrm{ROH})$ - see figure $4-$ nine phases $=0$, one phase $=0.538$

2. Relative Risks for phase in Treatment in Question $\left(R_{R T}\right)=R_{s c}(1.0)+R O H-$ nine phases $=1$, one phase $=1.538$

3. Observed risks for phase in Treatment in Question $\left(\mathrm{ORT}_{\mathrm{x}}\right)=\mathrm{RRT}_{\mathrm{x}} \times \mu$-nine phases $=15.2 \%$, one phase $=23.38 \%$

Step 3- Hypothesis Testing :

(A) Hypotheses -

1. Null Hypothesis: The treatment in question comports with the standard of care. (risk of treatment $=\mu$ )

2. Alternative Hypothesis: The treatment in question departs from the standard of care. (risk of treatment $>\mu$ )

(B) The Test - one sample t-test

1.The sample $\left(\mathrm{ORT}_{\mathrm{x}}\right.$ ): 15.2\%, 15.2\%, 15.2\%, 15.2\%, 15.2\%, 15.2\%, 15.2\%, 23.38\%, 15.2\%, 15.2\%

2.Level of significance, or alpha $(a)=0.05$

3.Population mean $(\mu)=15.2 \%$

(C) The Result $-\mathrm{P}$-value $=0.171718 .0 .171718>0,05$; therefore null hypothesis is retained

Step 4-The Final Report: Certifies that the burden of proof is satisfied and there is $95 \%$ confidence in the result. 
with fetal brain damage. It is indisputable that Erica Byrom is a teenager. While in Liberia, she receives no prenatal care. After arriving from Liberia, she is diagnosed with a sexually transmitted disease. When considering other observation, these give credence to warrant a $65 \%$ to $100 \%$ probability that fetal brain damage exists before admission.

Step 2 is the essence of deductive reasoning. Both types of reasoning affirm that even the standard of care results in an adverse outcome. This is the background risk. Unlike inductive reasoning, deductive reasoning directly employs the background risk in the methodology.

The background risk for brain damage in a premature newborn less than 1000 grams is $15.2 \%$ [20]. This $15.2 \%$ is absolutely unpreventable. Because the standard of care cannot exceed the background risk of $15.2 \%$, the risk in any phase in the standard of care is always $15.2 \%$. This corresponds to a relative risk of 1.0, which serves as the benchmark to which any increase in risk is added.

The correlation between cause and effect depends on the difference between each of the 10 phases in the treatment in question and their counterparts in the standard of care. Any difference results in a Risk of Harm ( $\mathrm{ROH})$, which is a calculation of the increase in risk that could have been avoided had the standard care for that phase been implemented instead. How risk of harm is determined depends on each individual case.

In Byrom vs Bayview Hospital, all phase of both the standard of care and treatment in question are impacted by those 11 words. The only variance is between the Technical Phases. The Technical phase in treatment in question is the discontinuation of electronic fetal monitoring and the exclusion of fetal indications for cesarean section. Because the likelihood of brain damage is determined to be, at least, $65 \%$, there is a $35 \%$ likelihood of averting brain damage by continuous electronic fetal monitoring and a cesarean section for fetal indications, which is the Technical phase in the standard of care. Risk of harm $=35 \% \div 65 \%=0.538$, which corresponds to a $53.8 \%$ increase in the relative risk. The nine other phases of the treatment in question have risks of harm of 0 (Figure 4).

Risk of harm for any phase in the treatment in question incrementally increases the relative risk over the benchmark (1.0). Therefore, the relative risk for any phase in the treatment in question equals 1.0 plus the risk of harm of that phase. Nine phases in the treatment in question have relative risks of $\mathbf{1 . 0}$ and the Technical Phase, has a relative risk of 1.538 .

Step 2 concludes with the observed risk. The product of the relative risk for any phase in the treatment in question and the background risk is the observed risk of that phase. Nine phases in the treatment in question have observed risks of $15.2 \%$ and the Technical phase has an observed risk of $23.38 \%$. These are the dependent variables that show how closely related the entire treatment in question is to the brain damage.

In step 3, the null hypothesis, which is the treatment in question comports with the standard of care, is tested with the one sample t-test [21]. The one sample t-test is best suited for analysis in medical malpractice because there is only one sample to be tested against a known population. In Byrom vs. Bayview Hospital, all ten observed risks for the treatment in question are the sample being tested against the standard of care which represents the background risk for brain damage in the general population of all premature infant under 1000 grams. Testing the null hypothesis shows, with $95 \%$ confidence (level of significance or $\alpha=0.05$ ), whether the brain damage is more closely related to the standard of care or more closely related to the treatment in question.

The result is the p-value. If greater than or equal to $\alpha$, 0.05 , the null hypothesis is retained; if less than 0.05 , the null hypothesis is rejected in favor of the alternative hypothesis, which is the treatment in question departs from the standard of care. In Byrom vs. Bayview Hospital the p-value $=0.171718$. The treatment in question comports with the standard of care and the brain damage would have occurred in any event. The null hypothesis is retained.

Step 4 is the final report. Ultimately, this is the most important evidence in a malpractice case. Using deductive reasoning, the report either affirms or rejects the null hypothesis and certifies that the opinion has been tested for validity with a specified level of significance of 0.05 , which corresponds to $95 \%$ confidence in the results and only a $5 \%$ risk of rejecting a true null hypothesis. This report is prepared even before pleadings are filed and answered; therefore if a judge later rules that certain details cannot be discussed, the cat is out of the bag and cannot be put back. This is how the maneuver is preempted.

\section{Conclusions - What gets measured gets managed}

In Byrom vs Bayview Hospital, the maneuver is a victory for plaintiff attorneys. For the judge, however, the maneuver is a mistake. The purpose of a Court of Appeals is to remedy such mistakes. On February 2, 2021, in a unanimous decision, the Maryland Court of Special Appeals overturns Byrom vs. Bayview Hospital [22]. Overturning this case on an appeal affirms everything thus far discussed. This is how the maneuver is defeated but it takes 16 months and the harm has been done. The medical liability litigation industry, including attorneys and expert witnesses, remains untouched.

It is widely acknowledged that there is a problem in medical malpractice litigation. Tort reforms seek to lessen the impact of suspicion of fault and, thereby, address the problem. They do so by measuring and managing financial incentives in lawsuits, such as, punitive damages, the incomes doctors earn as expert witnesses, contingency fees, collateral sources and joint and severable liability, but they do little else. However management science would pinpoint a focus more critical than these. That critical focus is the expert witness. As physicians, they have the most influence on the suspicion of fault.

The law requires of experts onus probandi, a burden of proof having no less than $50 \%$ probability plus a quantum. There is another requirement - primum non nocere. Above all else, do no harm. As yet, the significance of this dictum is unappreciated 


\section{Presentation Phase - Risk of harm $=0$}

(A)Treatment in question: Mother=16-year-old woman, 25 weeks of gestation, with severe pre-eclampsia Arrived in USA from Liberia. Started prenatal care at 23 week and at that time was diagnosed with chlamydia. Fetus=under 1000 grams. Until 17 weeks, fetal development occurs in Liberia.

(B)Standard of care: Same.

\section{Investigation Phase- Risk of harm $=0$}

(A) Treatment in question: $\underline{\text { Mother }}=$ workup for preeclampsia, bedrest, $\mathrm{MgSO} 4$, steroids. $\underline{\text { Fetus }}=2$ weeks ago, a routine screening sonogram is normal. A high-risk sonogram at 25 weeks looks at more specific finding, including umbilical artery doppler, AFIs, placental findings, and fetal growth patterns. Fetal monitoring

\section{(B) Standard of care: Same}

\section{Interpretation Phase - . Risk of harm $=0$}

(A) Treatment in question: Mother= hemolysis, elevating liver enzymes, decreasing platelets, increasing proteinuria and worsening blood pressures. Fetus: Findings of sonograms and continuous fetal monitoring consistent with placental insufficiency. Also considered is fetal development for first 17 weeks is influenced by conditions occurring in in Liberia.

(B) Standard of care: Same

\section{Diagnostic Phase - Risk of ham $=0$}

(A) Treatment in question: Mother $=\mathrm{dx}$ : HELLP syndrome and worsening pre-eclampsia. Prognosis- serious. $\quad \underline{\text { Fetus }}=\mathrm{dx}$ : A $65 \%$ probability of brain damage, considering all factors including those unique to Liberia, Prognosis-poor

(B) Standard of care: Same.

\section{Discrimination Phase - Risk of harm $=0$}

(A) Treatment in question: Mother= Late term abortion or immediate delivery. Cesarean section vs induction of labor. $\underline{F}$ Fetus $=$ considering all factors including those unique to Liberia prognosis is poor and prognosis is unaffected by mode of delivery. (B) Standard of care: Same.

\section{Informed Consent Phase - Risk of harm $=0$}

(A)Treatment in question: $\underline{\text { Mother }}=$ informed of alternatives including late term abortion - safer choice is induction. Fetus $=$ safer choice is cesarean section but $65 \%$ probability outcome is unpreventable when considering all factors including those unique to Liberia.

(B) Standard of care: Same.

\section{Selection Phase - Risk of harm $=0$}

(A) Treatment in question: Mother $=$ refused late term abortion. Chooses induction of labor reserving cesarean section for maternal indications. Fetus $=$ no cesarean section for fetal indications because of $65 \%$ probability outcome is unpreventable considering all factors including those unique to Liberia.

\section{(B) Standard of care: Same.}

\section{Technical Phase- Risk of harm $=0.538$}

(A) Treatment in question: Discontinue of electronic fetal monitoring. Induction using Cytotec and only maternal indication for cesarean section - There is, at least a $65 \%$ probability that there is already brain damage

(B) Standard of care: Continue electronic fetal monitoring. Induction using Cytotec, fetal and maternal indications for cesarean section, Thee is, at most, a $35 \%$ probability of averting brain damage

9. Resolution Phase- Risk of harm $=0$

(A) Treatment in question: Mother $=$ post-partum recovery from pre-eclampsia. Fetus $=$ most very-low-birth weight fetuses require resuscitation and have at least a $15.2 \%$ chance of brain damage

(B) Standard of care: Same.

\section{Discharge Phase- Risk of harm $=0$}

(A) Treatment in question: Mother $=$ discharged in good condition with outpatient follow visits. Fetus $=$ All 670-gram newborns remain in the NICU and at least $15.2 \%$ will have brain damage

(B) Standard of care: Same.

in medical malpractice; however, it effectually raises the threshold of quantum for medical experts. It does so because of two indisputable facts: (1) Ethical standards expressly require medical experts to be objective [23]. (2) As physicians, medical experts are accountable to this dictum.

The ethical obligation of medical experts would supersede any legal maneuver. Yet, in the Byrom case, experts cooperate.
This cannot happen with deductive reasoning. It is not that deductive reasoning is infallible. but its greatest asset is it is objective. As shown in the aforementioned model, these 11 words are necessarily examined as a matter of process. When an expert uses this model of deductive reasoning, the Presentation phase precludes intentionally dismissing these 11 words. An effort to deny any association with Liberia would require an inconceivable distortion of the Presentation phase 
in the standard of care. Attempting to do so is inexcusable misconduct and causes immeasurable harm.

Given a requirement to be objective and given deductive reasoning is objective, it follows that, to prevent another verdict like Byrom vs. Bayview Hospital, organized medicine needs only to adopt deductive reasoning as a best practice for all medical experts. Once a standard, unlike experts in Byrom vs Bayview Hospital, if experts are again faced with a choice between a legal maneuver and an ethical duty, they will recuse themselves because cooperating with the maneuver is answerable to the medical profession. Any resulting disciplinary action has profound consequences.

Essentially, deductive reasoning measures and manages quantum in the burden of proof and, by so doing, it manages medical experts. There is no legislation, no political posturing, no Court of Special Appeals and no need to seek the agreement or approval of the medical liability litigation industry.

\section{References}

1. Belk D (2020) True cost of healthcare. Malpractice Statistics. Link: http://bit.ly/3dINeTY

2. Best Lawyers for Medical Malpractice Law -Plainfiffs in America (2020) Best Lawyers. Best Legal Malpractice Law - Plaintiffs Lawyers in America. Best Lawyers. Link: http://bit.ly/2P9XASN

3. Best Lawfirms for Medical Malpractice Law - Defendants (2020) US News Best Law Firms for Medical Malpractice Law - Defendants. (usnews.com) Link: http://bit.ly/3utLoMM

4. Member Directory (2020) Medical Professional Liability Association. Member Directory (mplassociation.org). Link: http://bit.ly/3dLIs9|

5. Ryskamp DA (2020) Why you should work with an expert witness referral service. Expert Institute. Why You Should Work With An Expert Witness Referral Service (expertinstitute.com). Link: http://bit.ly/3pSXmw7

6. Doroshow J (2017) Over 80 national and state organizations ask US House to reject bill limiting patient's rights. Center for Justice and Democracy. Group Letter to U.S. House of Representatives Opposing Med Mal Nursing Home Drug Bill centerjd.org. Link: http://bit.ly/3pTT1IK

7. Luebsdorf J (2019) Does the American Rule promote access to justice? Duke Law Journal. Does The American Rule Promote Access to Justice? Was Tha Why It Was Adopted? | Duke Law Journal. Link: http://bit.ly/3kky88s

8. The American Tort Reform Association American Tort Reform Association ATRA. Link: http://bit.ly/2ZOKFI8

9. Hauser MJ, Commons ML, Bursztajn HJ, Gutheil TG (2020) Fear of malpractice liability and its role in clinical decision making. PIPATI. Fear of Malpractice Liability and its Role in Clinical Decision Making (pipatl.org). Link: http://bit.ly/37K0Cnb

10. Crisler R (2020) The burden of proof in medical liability cases: a preponderance of evidence. AAOS Bulletin. Link: http://bit.ly/2NBOP3q

11. Ep 032, Great Trial Podcast. Link: http://bit.ly/3r59hrK

12. Plaintiff closing argument. Transcripts of official proceedings. Static 1 SquareSpace. Com. 5 -20 and 52-70. Link: https://bit.ly/3qSVrbT
13. Defense closing argument. Transcripts of official proceedings. Static 1 SquareSpace. Com. 20-52. Link: https://bit.ly/3qS

14. VrbT Verdict sheet. Static 1 Square Space. Com 48-49. Link: https://bit.ly/3kn3vzo

15. Complaint and demand for jury trial. Static 1 Square Space.Com. 5 In. 27. Link: https://bit.ly/3kkwVhq

16. Federal rules of civil procedure. The Committee on the Judiciary House of Representatives. Link: https://bit.ly/3uu9Sp3

17. Murphy J (2020) Mind-boggling medical malpractice claims. MDLinx. Link: https://bit.ly/3sCZNVp

18. Federal rules of evidence. The Committee on the Judiciary House of Representatives. Link: https://bit.ly/3uuiOuO

19. Blackstone SR (2020) Evaluating antenatal care in Liberia: evidence from demographic and health survey. Women Health 59: 1141-1154. Link: http://bit.ly/3pPIz51

20. Robertson MTC, Watt MJ, Yasui Y (2007) Changes in the prevalence of cerebral palsy for children born very prematurely within a population-bases program over 30 years. JAMA 297: 2733-2740. Link: http://bit.ly/3bBjCoT

21. Single sample t-test calculator. Social Science Statistics (2020). Link: http://bit.ly/3kIFicl

22. McKenna O (2021) Maryland Court of Special Appeals overturns \$205 million birth injury verdict against Johns Hopkins Bayview - Baltimore Sun. Link: http://bit.ly/2NWOyJW

23. Guidelines on the ethical conduct of the expert witness. ACLM. Link: https://bit.ly/3qWEbCW

\section{Discover a bigger Impact and Visibility of your article publication with}

\section{Peertechz Publications}

\section{Highlights}

* Signatory publisher of ORCID

* Signatory Publisher of DORA (San Francisco Declaration on Research Assessment)

* Articles archived in worlds' renowned service providers such as Portico, CNKI, AGRIS, TDNet, Base (Bielefeld University Library), CrossRef, Scilit, J-Gate etc.

* Journals indexed in ICMJE, SHERPA/ROMEO, Google Scholar etc.

* OAI-PMH (Open Archives Initiative Protocol for Metadata Harvesting)

* Dedicated Editorial Board for every journa

* Accurate and rapid peer-review process

* Increased citations of published articles through promotions

* Reduced timeline for article publication

Submit your articles and experience a new surge in publication services (https://www.peertechz.com/submission).

Peertechz journals wishes everlasting success in your every endeavours.

Copyright: () 2021 Smith HN. This is an open-access article distributed under the terms of the Creative Commons Attribution License, which permits unrestricted use, distribution, and reproduction in any medium, provided the original author and source are credited. 